\section{Cine español del nuevo milenio}

\section{Spanish Cinema of the New Millennium}

Fechas | En edición: 29/04/2020 - Publicación final: 01/07/2020

\section{Luis-Miguel MACHÍN-MARTíN}

Universidad de La Laguna. España. Imachinm@ull.es

\section{Spanish Cinema of the New Millennium}

Autor: Thomas G. DEVENY

Bristol: Intellect Books, 2019.

275 páginas

ISBN: 9781789380064

Ebook: 9781789380071

\section{Resumen}

Los últimos 15 años han sido un periodo de transformación en la industria del cine español, tanto en lo referente a las formas de producción como en los gustos de la audiencia. Este libro analiza ese espacio en el cine español, haciendo hincapié en el canon modelado por la academia española y cómo ese canon encaja en con las audiencias, además de estudiar cómo han variado los temas representados en las películas más vistas y premiadas del periodo en España.

\section{Palabras clave}

Cine español; canon cinematográfico; Premios Goya.

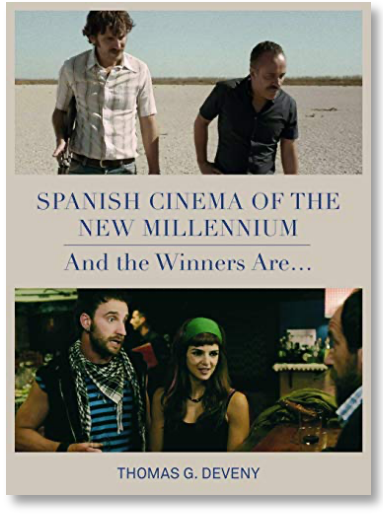

\section{Abstract}

The last 15 years have been a period of change in the Spanish film industry, both in terms of ways of production and the tastes of the audience. This book analyzes that space of time in Spanish cinema, emphasizing the canon modeled by the Spanish Academy and how that canon fits in with the audience, in addition to studying how the themes represented in the most viewed and awarded films of the period in Spain.

\section{Keywords}

Spanish Cinema; film canon; Goya Awards. 
Afrontar el análisis de una cinematografía expuesta a continuos cambios en las formas de financiación y producción, con vaivenes artísticos y resultados irregulares en taquilla, como se trata de la española, es una tarea compleja y llena de trampas. Tratar, además, de detectar las tendencias artísticas, académicas y comerciales también lo es. Por eso, la propuesta que hace Thomas G. Deveny con su libro Spanish Cinema of the New Millennium podría considerarse arriesgada, pero solventa las dificultades de un estudio de este tipo a través de una propuesta que individualiza cada caso analizado y que, al final, permite obtener conclusiones.

El punto de partida esta obra es la de analizar el filme ganador del Goya a la mejor película y la película española más taquillera de cada año en el periodo comprendido entre 2000 y 2015. De este modo, Deveny analiza dos elementos: el canon que construye la propia academia española a través del ganador de su mayor premio, es decir, de la mejor y más importante película española producida cada año según la propia industria del cine; y lo que ven los espectadores, es decir, qué gustos tiene el público español, cómo estos van evolucionando, qué relación tienen las obras con más espectadores con la propia industria española y cómo contrastan esos gustos con los premios Goya.

Divide estructuralmente el libro en cuatro partes bien diferenciadas: una potente introducción donde desglosa las complejidades de un análisis de este tipo en la industria española; tres capítulos donde analiza año a año la ganadora al premio goya y la película española más taquillera, con el análisis de 5 películas por capítulo; un cuarto capítulo, donde se examinan tendencias entre las películas estudiadas; y una última parte de apéndices y anexos que complementan el estudio.

Thomas G. Deveny fija un objetivo como punto de partida: "This study analyzes the films that Spanish Society deems the most important in the new millennium (...) in order to examine questions of national identity in relation to the Spanish cinematic industry» (p. 3). Ese objetivo será desarrollado en la introducción, en la que también afronta temas como qué es el cine español, qué representa el cine español en sus historias, qué hace que una película sea española -a nivel de identidad cultural y a nivel de producción-o qué es cine popular en España. Por ejemplo, en cuanto al cine popular, el autor se pregunta si la popularidad comercial de una película española tiene que ver con la cantidad de público que lo ve, con los premios que gana o con quién lo dirige, cuestión extensible a otras cinematográficas. Con respecto a qué hace a una película española, Deveny reflexiona: «Spanish national identity with regard to the film industry is an even more complicated question, becase from the very beginning, Spanish film has had transnational components» (p. 5), haciendo referencia, en especial, a la figura de Segundo de Chomón, que desempeñó diferentes labores en producciones francesas o italianas, por lo que puede entenderse que el propio origen del cine español no es enteramente español. Así, reflexionando sobre los límites de qué es lo español en el cine español, el autor construye un contundente pero condensado marco teórico con el que ofrece herramientas para interpretar y contextualizar correctamente el contenido posterior.

Cuando Deveny entra en materia y comienza a ofrecer el análisis de las películas, llama la atención una particularidad: construye su análisis y su discurso, en gran medida, con citas de otros autores. Pero lo hace de una forma muy natural, como si el análisis de cada película no fuera una cuestión individual del propio autor del libro sino un compendio y, si se quiere, un consenso, sobre lo que significó el éxito académico y/o comercial de cada película glosada. En ese sentido, Spanish Cinema of the New Millennium es una herramienta muy útil para entender los porqués del éxito de ciertas películas españolas desde varios ángulos diferentes y sin adoptar una visión personal y unidimensional del asunto.

Tras realizar un análisis cultural, industrial y comercial de cada película -el espacio dedicado a cada película va desde breves reseñas de un par de páginas a estudios más extensos, como el de la película Camino (J. Fesser, 2008), que se desarrolla en 8 páginas- el autor obtiene tendencias, hallazgos y ciertos tics en el cine español de los tres primeros lustros del siglo XXI. Por ejemplo, Deveny expone la tendencia a producir cine rodado en inglés con actores extranjeros, y pone como ejemplo películas como La vida secreta de las palabras (I. Coixet, 2005), Ágora (A. Amenábar, 2009), Lo imposible (J. A. Bayona, 2013), Los otros (A. Amenábar, 2001) o Los crímenes de Oxford (Álex de la Iglesia, 2007). Con respecto a esta cuestión el autor se pregunta: "To what extent did this glamor [se refiere a rodar en inglés con actores internacionales] help Amenábar win at the Spanish box office?», y añade, "And to what extent did the glamor of filming in English with international stars help Isabel Coixet win the Goya for The Secret Life of Words?) (p. 196). De estas preguntas subyacen reflexiones acerca de la identidad tradicional del cine español (¿̇el cine español sigue siendo español si su lengua e intérpretes no son españoles?) y sobre los gustos de la audiencia, que, queriendo distanciarse de cierto tipo de cine español, pueden sentirse atraídos por películas que precisamente no hablen de lo español ni reproduzcan historias españolas cuestión sobre la que el autor reflexiona en diferentes capítulos, y que ya adelanta en la introducción del libro, mencionando expresamente el concepto de españolada (p. 4). 
Este libro, por tanto, se sumerge de lleno en las complicadas aguas de la industria española del siglo XXI poniendo énfasis en las cuestiones de la identidad y de la cultura española en relación con la audiencia. Aunque más que como estudio industrial y cultural, la obra puede leerse como una fotografía que retrata el estado del cine español en el periodo estudiado, y como tal el libro es una herramienta útil si se quiere entender las razones que llevaron a ciertas películas españolas a tener éxito y cómo eso se relaciona con la propia sociedad española y con lo que una parte de la sociedad quiere proyectar de sí misma. 